SRNL-STI-2011-00349

\title{
Preliminary Study of Methods to Chemically Bind Zinc
}

\author{
Paul Korinko
}

June 10, 2011

\section{Savannah River National Laboratory Savannah River Nuclear Solutions Savannah River Site Aiken, South Carolina}

This document was prepared in connection with work done under Contract No. DE-AC09-08SR22470 with the U.S. Department of Energy. By acceptance of this document, the publisher and/or recipient acknowledges the U.S. Government's right to retain a nonexclusive, royalty-free license in and to any copyright covering this document, along with the right to reproduce and authorize others to reproduce all or part of the copyrighted material. 


\section{SRNL-STI-2011-00349}

\section{Preliminary Study of Methods to Chemically Bind Zinc}

\section{Table of Contents}

Summary

\section{List of Tables}

Table 1. Conditions tested and weight of deposit for copper and cobalt ......................................... 5

Table 2. XRD results for a copper screen exposed at $400^{\circ} \mathrm{C}$ compared to the target copper - zinc compounds-Major peaks from $2 \theta=20$ to $100^{\circ}$

\section{List of Figures}

Figure 1. Photographs of zinc TVD apparatus and conical reaction vessel used for this study. ............. 6

Figure 2. Copper screen and cobalt rods used for this study. As received condition.......................... 7

Figure 3. Results of Monte Carlo Simulations for $10 \mathrm{keV}$ and $4 \mathrm{keV}$. Note the smaller interaction volume and depth for the $4 \mathrm{keV}$. The values are consistent with the density based calculated

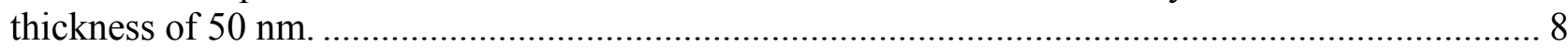

Figure 4. Typical data output from an experiment. Data from a $400^{\circ} \mathrm{C}$ cobalt and $410^{\circ} \mathrm{C}$ zinc run are

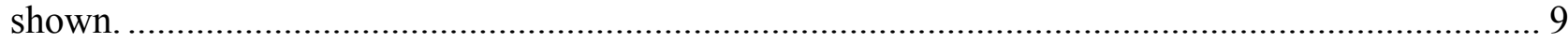

Figure 5. XPS results from the copper sample exposed at $400^{\circ} \mathrm{C}$. Note the presence of the $\mathrm{K} \alpha$ and $\mathrm{K} \beta$ peaks.

Figure 6. SEM and EDS results for areas of interest from the copper screen exposed at $350^{\circ} \mathrm{C} \ldots \ldots \ldots . . .11$

Figure 7. SEM and EDS results for areas of interest from the copper screen exposed at $400^{\circ} \mathrm{C} \ldots \ldots \ldots \ldots 12$

Figure 8. SEM and EDS results for areas of interest from the copper screen exposed at $450^{\circ} \mathrm{C} \ldots \ldots \ldots . . .13$

Figure 9. XRD results for the cobalt rod exposed at $400^{\circ} \mathrm{C}$. Note apparent absence of zinc and presence

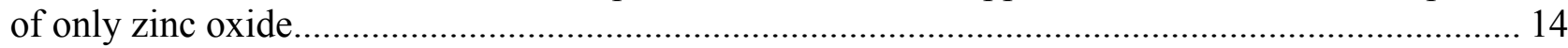

Figure 10. XRD results from zinc that was deposited in the vaporization chamber to confirm that zinc is primary species present. Note presence of zinc oxide as well. 


\section{Preliminary Study of Methods to Chemically Bind Zinc}

\section{Summary}

To address the ${ }^{65} \mathrm{Zn}$ contamination issue in the TEF, a multi-task experimental program was initiated. The first two experimental tasks were completed $[1,2]$. The results of the third experimental task are reported here. This task was conducted to determine if the zinc vapors could be chemically bound on two non hydrogen active substrates. Based on a thermodynamic study [3] copper and cobalt were the most favorable for capturing zinc without forming hydrides. Within the experimental parameters tested, which include temperatures of 350,400 , and $450^{\circ} \mathrm{C}$ at pressures of nominally $20-40$ millitorr, the zinc deposited on the both copper screen and cobalt rods but did not react to form a compound. The conditions that were tested are not prototypic and additional testing under higher vacuum conditions, i.e., .01 millitorr, may enhance the reactivity of the surfaces and is recommended.

\section{Background}

Radioactive zinc $65\left({ }^{65} \mathrm{Zn}\right)$ has been extracted from irradiated TPBARs at levels that produce a signature greater than background. Review of the potential sources of ${ }^{65} \mathrm{Zn}$ from the TPBAR sub-elements indicates that it is an activation product of natural zinc and that it is present as a low level contaminant in several of the TPBAR materials $(5,6,7)$. The results from the initial post-mortem examination of the piping removed from the TEF, and a literature review of vapor phase deposition indicated that certain conditions may be beneficial to the growth of the zinc whiskers. Consequently $20 \mu \mathrm{m}$ filters heated to $200^{\circ} \mathrm{C}$ were installed in key areas of the TEF process lines (6). The subsequent post-mortem examination of the filters, especially gamma scans, indicated that ${ }^{65} \mathrm{Zn}$ had been trapped within these locations, although the deposit morphology was difficult to characterize due to the presence of native $\mathrm{Zn}$ on the filters (7). These results lead TEF to sponsor this effort to optimize filter capturing and evaluate the possibility of capturing zinc within the lithium trap.

An experimental program was initiated to develop and validate conditions that will effectively trap $\mathrm{Zn}$ vapor released during extraction in the TEF. The work was divided into three experimental tasks and a literature/thermodynamics study. The first experimental task was to determine the effectiveness of various pore sizes of filter elements (1) which revealed that $20 \mu \mathrm{m}$ filters would be effective to trap the zinc vapor. The second task was to determine the effect of filter temperature on zinc vapor deposition (2) which resulted in a recommendation that the filters be heated to between 120 and $200^{\circ} \mathrm{C}$. The thermodynamics study (3) indicated that copper and cobalt may be effective at trapping zinc in a chemical form while avoiding forming hydrides. If it is possible to capture the contaminants chemically in the lithium trap, then the contamination would remain in the high radiation area, which would reduce potential dose to the worker. The final experimental task is to determine whether the zinc vapors can be chemically bound at conditions typical of the lithium trap. The overall approach for capturing the zinc vapors is described in Ref. 4. This report details the results of preliminary experimental testing to determine if zinc vapor can be chemically bound to either copper or cobalt. 


\section{Experimental}

The evaporation vessel and filter assembly system used in the pore and temperature optimization studies $(1 \& 2)$ were modified for this study. The filter holder was removed and replaced with a larger conical chamber to support the copper screen and cobalt rods, Figure 1. Sample articles, Figure 2, were weighed, placed in the conical section of the apparatus, and the chamber was evacuated to less than 50 mTorr. There as no pre-weighing sample preparation for the copper screen, it was tested in the asreceived condition; while the cobalt rods were lightly abraded with 600 grit silicon carbide paper to remove surface oxides and swiped with alcohol to remove grinding residue. The system was held under vacuum for a minimum of 2 hours prior to heating the conical section to the target temperature. The conical section was heated to the exposure temperature for 30 minutes prior to heating the zinc containing vessel above the vaporization temperature. To reduce the moisture content, the zinc vessel was heated to $150^{\circ} \mathrm{C}$ and held for 30 minutes, then the vessel was heated to 400 to $430^{\circ} \mathrm{C}$ to ensure adequate zinc vapor; the zinc source was held at temperature for 3 hours and the conical section was held at temperature the entire time the zinc vessel was above $300^{\circ} \mathrm{C}$. The system was pumped the entire time using a scroll pump.

The samples were weighed after being exposed to the zinc vapor. If weight gain was observed, then the samples were examined using X-ray Diffraction (XRD) using copper K $\alpha$ radiation, X-ray Fluorescence (XRF), Scanning Electron Microscopy (SEM), and X-ray Energy Dispersive Spectroscopy (EDS). The SEM was conducted after using a Monte-Carlo simulation to quantify the beam interaction volume and improve the chemistry by choosing the optimal accelerating voltage of the electron beam. Electron beam accelerating voltages of both 4 and $10 \mathrm{keV}$ were used for imaging and $4 \mathrm{keV}$ was used for EDS. Figure 3 shows the relative interaction volumes and depth for the expected copper - zinc compounds based on the Monte Carlo simulations.

\section{Results}

A typical data plot for a run in which the reaction chamber was heated to $400^{\circ} \mathrm{C}$ and the zinc vessel was heated to $400^{\circ} \mathrm{C}$ is shown in Figure 4. This plot indicates the increased dwell time for the reaction vessel (conical section) and the off-gassing heat-up for the zinc containing vessel. Unlike the previous filter runs where the pressure increased during the duration of the run, these runs had a lower starting vacuum, a lower operating vacuum, and a decreasing vacuum level with time. Consistent with previous experiments, the pressure decreased when the vessel temperature dropped to below $300^{\circ} \mathrm{C}$. All of the runs exhibited similar heat and vacuum profiles.

Figure 5 shows the XPS data from the copper filter heated to $400{ }^{\circ} \mathrm{C}$. The copper peaks are very strong, as expected, while there are smaller $\mathrm{Zn}$ peaks. These low level $\mathrm{Zn}$ peaks are consistent with the low weight gains that were observed. The presence of both the $\mathrm{K} \alpha$ and the K $\beta$ in the XPS data prove the presence of zinc.

XRD was used to see if the $\mathrm{Zn}$ had opportunity to react with the copper screen. These results were inconclusive. The measured and expected peaks are compared in Table 1 . It can be seen that the $2 \theta$ values most closely align with copper or copper $5 \% \mathrm{Zn}$ rather than the compound $\mathrm{CuZn}$. 
Due to the inconclusive nature of the XRD and XPS results, samples from each reaction vessel temperature test, 350,400 , and $450^{\circ} \mathrm{C}$ were examined on the SEM. Selected areas of the copper screen samples for the three exposure temperatures are shown in Figures 6, 7, and 8, respectively. The $350^{\circ} \mathrm{C}$ exposure did not exhibit any deposition of zinc either particles or more desired, zinc reaction products since no $\mathrm{Zn}$ was detected in the areas examined. Both the 400 and $450^{\circ} \mathrm{C}$ exposures exhibited zinc deposits, but they were discrete particles, much like those observed in the filter optimization activities for both temperature and pore size.

The cobalt samples were not examined to the same extent as the copper screen. The first cobalt rod that was exposed at $400^{\circ} \mathrm{C}$ exhibited a friable coating that was readily removed during handling and weighing. This rod was tested for zinc deposition using XRD and the results are shown in Figure 9. Note that only cobalt and zinc oxides were detected. Due to the lack of metallic zinc being detected, XRD was performed on zinc that is deposited during the run. A stainless steel rod was installed in the zinc vaporization chamber and a standard run was conducted. The zinc was scraped from the rod and tested analyzed with the results shown in Figure 10.

\section{Discussion}

Thermodynamically it is possible to form zinc and cobalt intermetallic compounds (3). Unfortunately, thermodynamics only indicates the conditions under which these compounds can form, it does not proscribe conditions under which the will form. The conditions that were used for these experiments had somewhat poor vacuum, tens of millitorr. It is possible that higher vacuum levels, say in the tenths to hundredths of a millitorr, may enhance the reactivity. There is adequate oxygen in the system to form some oxides as evidenced by the deposit on the cobalt rod. It is proposed that a series of experiments be conducted under higher vacuum. Further, testing at higher temperatures than was possible for the filter elements may enable some trapping of the zinc vapors in the lithium trap thus minimizing dose in the glovebox area of the TEF.

\section{Conclusions}

The higher temperature and vacuum conditions tested did not result in zinc compound formation on either copper or cobalt. Additional testing is warranted to see if zinc can be chemically bound at higher vacuum conditions.

\section{Acknowledgements}

I would like to acknowledge the contributions of Adrian Mendez-Torres for the Monte Carlo simulation, SEM and EDS work, in addition to the XRD work. I would also like to acknowledge Donna Hasty for financial and programmatic support and Kevin Stoner for technical support. 


\section{References}

1. SRNL-L4400-2010-00003, Zinc Mitigation Interim Report -- Effect of Pore Size, P. Korinko, Dec. 17,2010

2. SRNL-L4410-2011-00008, Zinc Mitigation Interim Report -- Effect of Filter Temperature on Trapping, March 31, 2011

3. SRNL-L4410-2010-00001, Zinc Mitigation Interim Report - Thermodynamic Study, P.S. Korinko, Dec. 17, 2010

4. SRNL-L7100-2010-00019, ${ }^{65} \mathrm{Zn}$ Trapping and Containment Optimization, P. Korinko, 5/2010

5. TTP-1-3003, White paper to Address Contamination Issues in TEF, E.F. Love, 2008.

6. SRNL-L7100-2008-00001, Analysis of TEF Pipe with ${ }^{65} \mathrm{Zn}$ Contamination P. Korinko, M. Tosten, Z. Nelson, 9/2008

7. SRNL-L7100-2010-00008, Examination of TEF Filters for ${ }^{65} \mathrm{Zn}$ Trapping, Paul Korinko, Michael Tosten, Zane Nelson, 2/2010

8. SRNL-LM200-2009-00013, Recommendations for TEF to Minimize Further Contamination of ${ }^{65} \mathrm{Zn}$, Paul Korinko, Robert Malstrom, and Andrew Duncan, 4/2009

9. SRNL-L7100-2010-00034, Examination of New Filter Media used for Zn Coalescing Filters, Paul Korinko, 8/2010

10. SRNL-L7100-2010-00039, Zinc Deposition R\&D Direction, P. Korinko, 11/2010. 
Table 1. Conditions tested and weight of deposit for copper and cobalt

\begin{tabular}{|l|l|l|l|l|}
\hline Test & Zinc Source SP $\left({ }^{\circ} \mathrm{C}\right)$ & Zinc Sink $\left({ }^{\circ} \mathrm{C}\right)$ & Mass $(\mathrm{mg})$ & Comments \\
\hline 1 Copper & 400 & 350 & 0.7 & Some gray wires \\
\hline 2 Copper & 400 & 400 & 0.3 & Some free $\mathrm{Zn}$ \\
\hline 3 Copper & 400 & 400 & 0.8 & Gray wires \\
\hline 4 Copper & 400 & 450 & 0.3 & \\
\hline 5 Cobalt & 400 & 400 & 0.0 & No deposit \\
\hline 6 Cobalt & 415 & 0.0 & $\begin{array}{l}\text { Easily removed } \\
\text { deposit }\end{array}$ \\
\hline
\end{tabular}

Table 2. XRD results for a copper screen exposed at $400^{\circ} \mathrm{C}$ compared to the target copper - zinc compounds-Major peaks from $2 \theta=20$ to $100^{\circ}$.

\begin{tabular}{|c|c|c|c|c|c|c|c|c|c|c|c|c|c|c|c|c|}
\hline \multirow[t]{2}{*}{ Peak } & \multicolumn{2}{|l|}{ Sample } & \multicolumn{2}{|c|}{$\begin{array}{l}\mathrm{Cu} \\
00-001-1242\end{array}$} & \multicolumn{2}{|c|}{$\begin{array}{l}\mathrm{Cu}-5 \% \mathrm{Zn} \\
01-071-7928\end{array}$} & \multicolumn{2}{|c|}{$\begin{array}{l}\mathrm{Cu}_{4} \mathrm{Zn} \mathrm{Hex} \\
03-065-6066\end{array}$} & \multicolumn{2}{|c|}{$\begin{array}{l}\mathrm{Cu}_{3} \mathrm{Zn} \text { Cubic } \\
03-065-6567\end{array}$} & \multicolumn{2}{|c|}{$\begin{array}{l}\mathrm{Cu}_{2} \mathrm{Zn} \\
00-058-0457\end{array}$} & \multicolumn{2}{|c|}{$\begin{array}{l}\mathrm{CuZn} \\
00-026-0571\end{array}$} & \multicolumn{2}{|c|}{$\begin{array}{l}\text { Zn Hex } \\
01-071-3764\end{array}$} \\
\hline & $2 \theta$ & I & $2 \theta$ & I & $2 \theta$ & I & $2 \theta$ & I & $2 \theta$ & I & $2 \theta$ & I & $2 \theta$ & I & $2 \theta$ & I \\
\hline 1 & 44.024 & 100 & 43.47 & 100 & 43.27 & 100 & 37.86 & 27 & 42.67 & 100 & 41.93 & 80 & 25.80 & 100 & 36.30 & 39 \\
\hline 2 & 51.026 & 88 & 50.37 & 53 & 50.39 & 42 & 42.05 & 25 & 49.69 & 43.1 & 43.02 & 100 & 26.75 & 40 & 39.00 & 24 \\
\hline 3 & 74.713 & 58 & 74.00 & 33 & 74.04 & 17 & 43.52 & 100 & 72.90 & 17.8 & 49.24 & 70 & 41.80 & 60 & 43.23 & 100 \\
\hline 4 & 90.442 & 73 & 89.93 & 33 & 89.82 & 16 & 57.85 & 11 & 93.38 & 4.4 & 50.24 & 70 & 43.52 & 20 & 54.33 & 14 \\
\hline 5 & 95.620 & 15 & 95.57 & 9 & 95.02 & 4 & 68.37 & 11 & & & 73.03 & 50 & 48.90 & 20 & 70.10 & 15 \\
\hline 6 & & & & & & & 77.86 & 10 & & & 77.55 & 10 & 50.14 & 40 & 70.65 & 10 \\
\hline 7 & & & & & & & 80.90 & 1 & & & 88.47 & 50 & 52.58 & 10 & 77.08 & 2 \\
\hline 8 & & & & & & & 83.62 & 10 & & & 92.99 & 40 & 55.40 & 10 & 82.11 & 11 \\
\hline 9 & & & & & & & 84.62 & 7 & & & & & 62.30 & 10 & 83.77 & 1 \\
\hline 10 & & & & & & & 91.71 & 1 & & & & & 72.29 & 20 & 86.56 & 7 \\
\hline 11 & & & & & & & 95.70 & 1 & & & & & 77.92 & 20 & 89.95 & 2 \\
\hline 12 & & & & & & & & & & & & & 87.59 & 20 & 94.91 & 2 \\
\hline
\end{tabular}


SRNL-STI-2011-00349

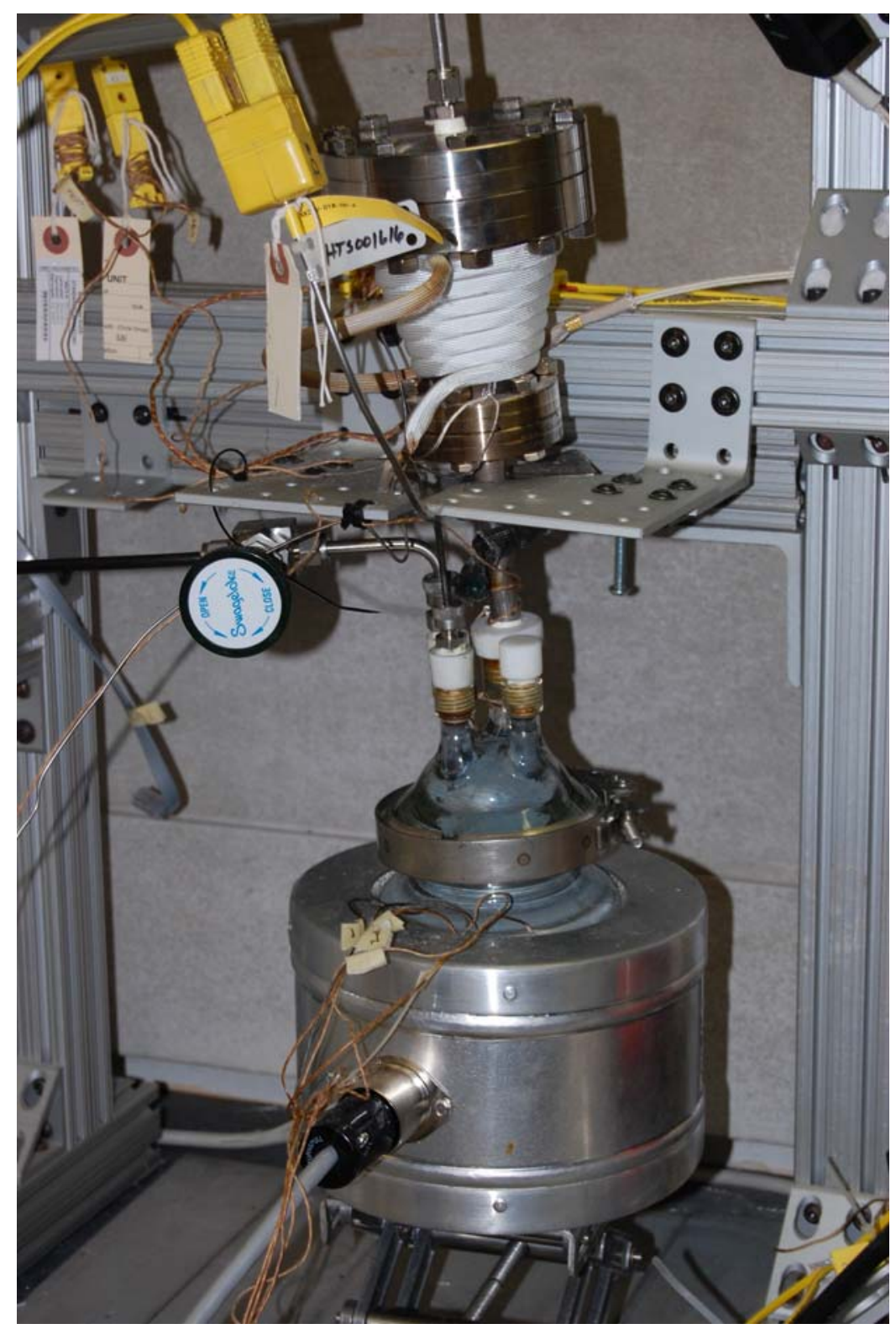

Page 6

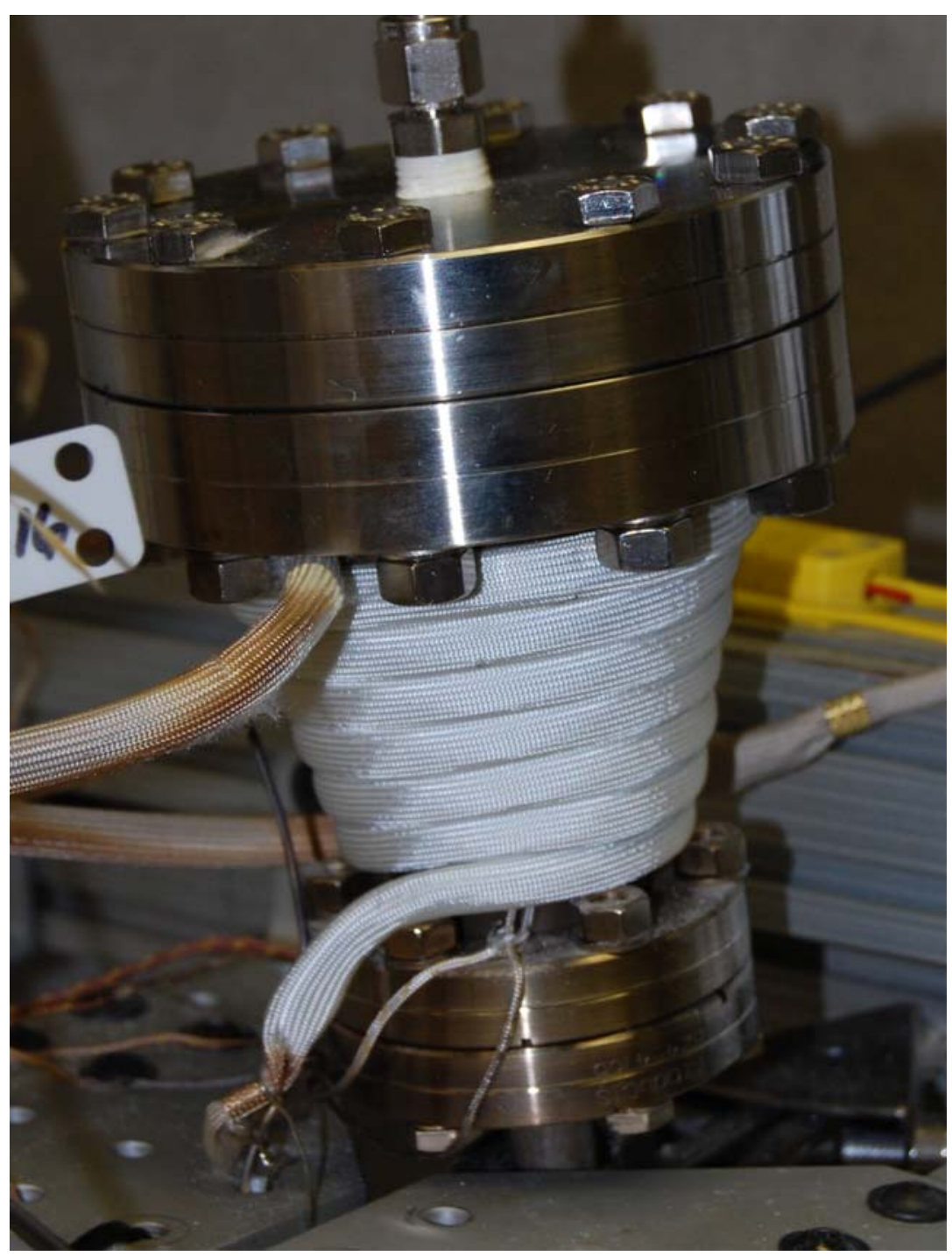

Note: \#\#-\#\#\#-\#\#\#\# Powder Diffraction Pattern reference data.

Figure 1. Photographs of zinc TVD apparatus and conical reaction vessel used for this study. 

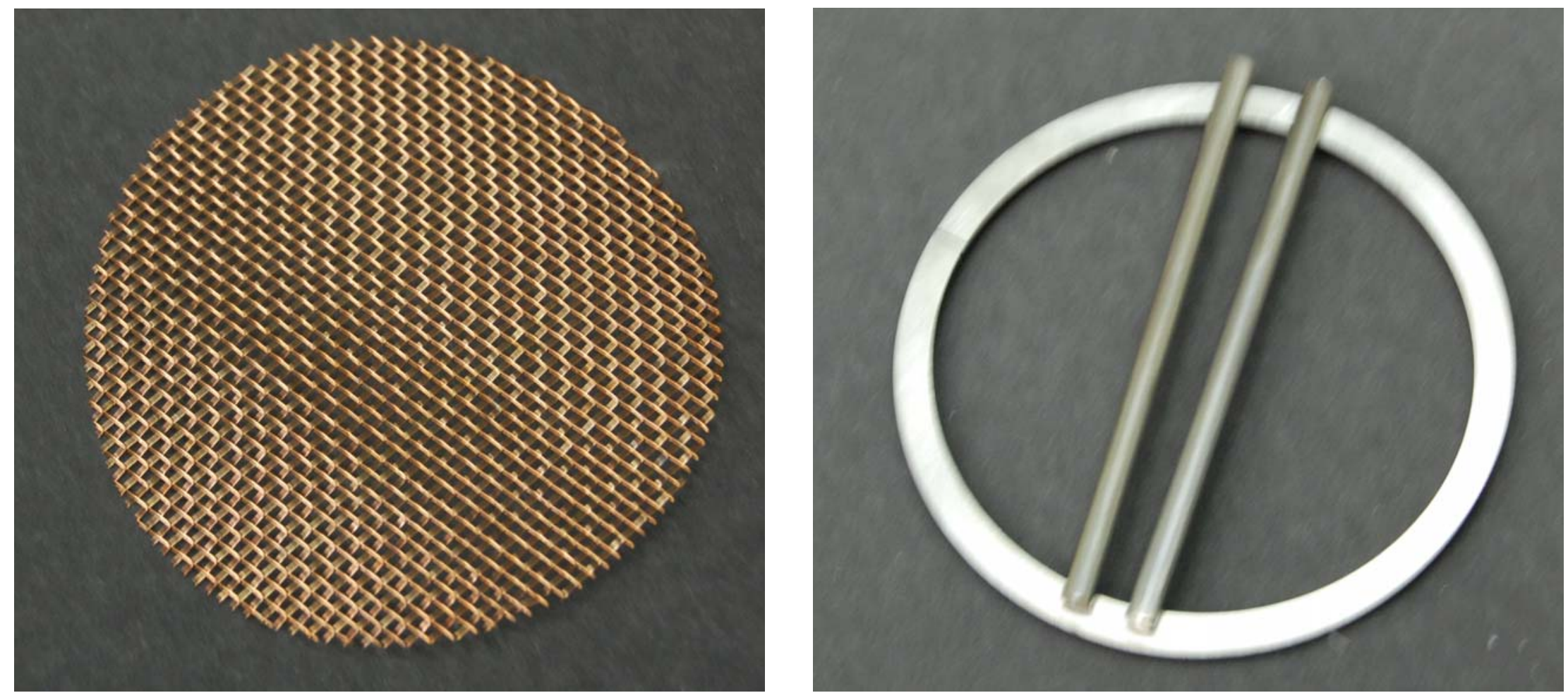

Figure 2. Copper screen and cobalt rods used for this study. As received condition. 

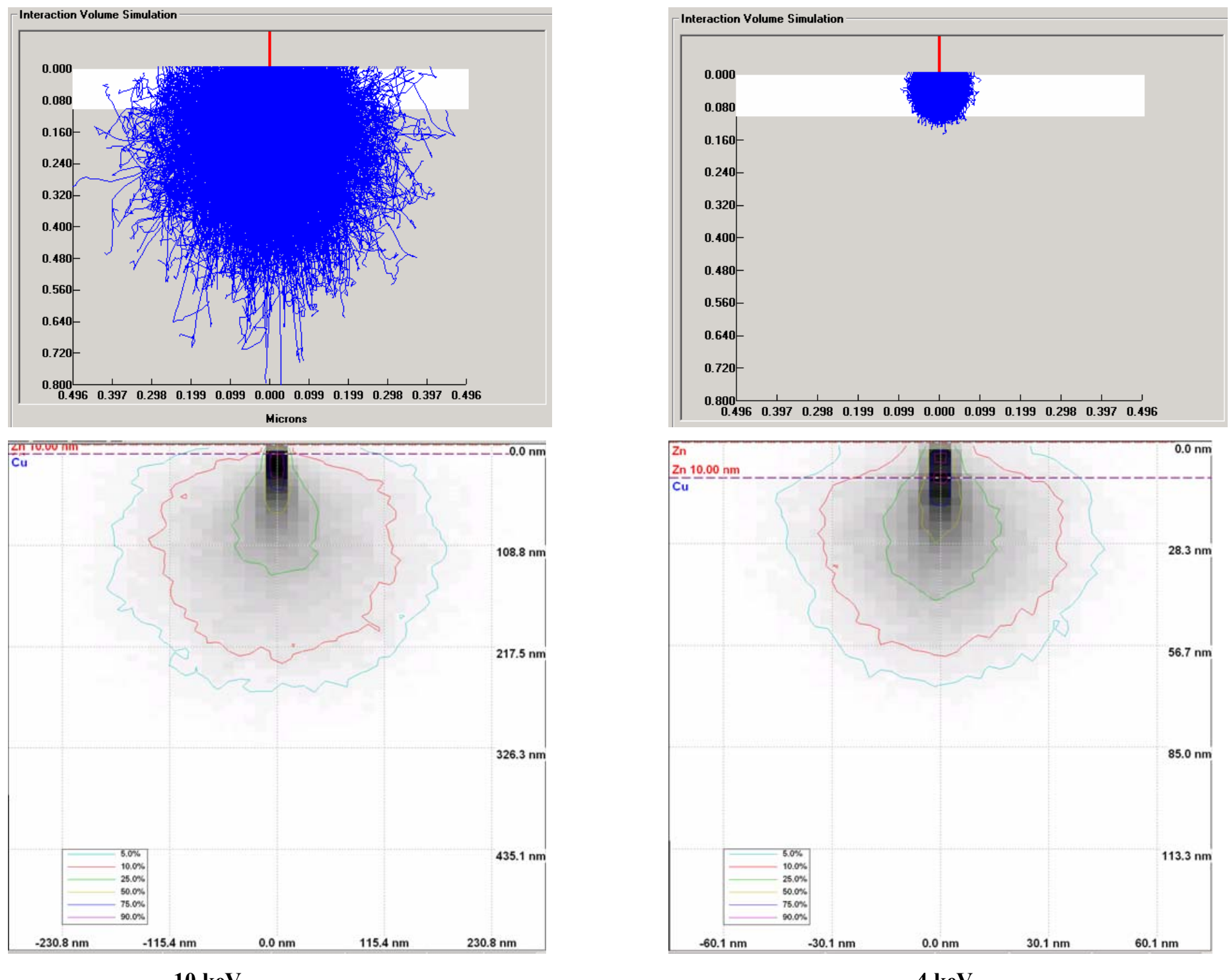

$10 \mathrm{keV}$

$4 \mathrm{keV}$

Figure 3. Results of Monte Carlo Simulations for $10 \mathrm{keV}$ and $4 \mathrm{keV}$. Note the smaller interaction volume and depth for the $4 \mathrm{keV}$. The values are consistent with the density based calculated thickness of $50 \mathrm{~nm}$. 


\section{Co $400 \mathrm{C}$ Filter $410 \mathrm{C}$ source}

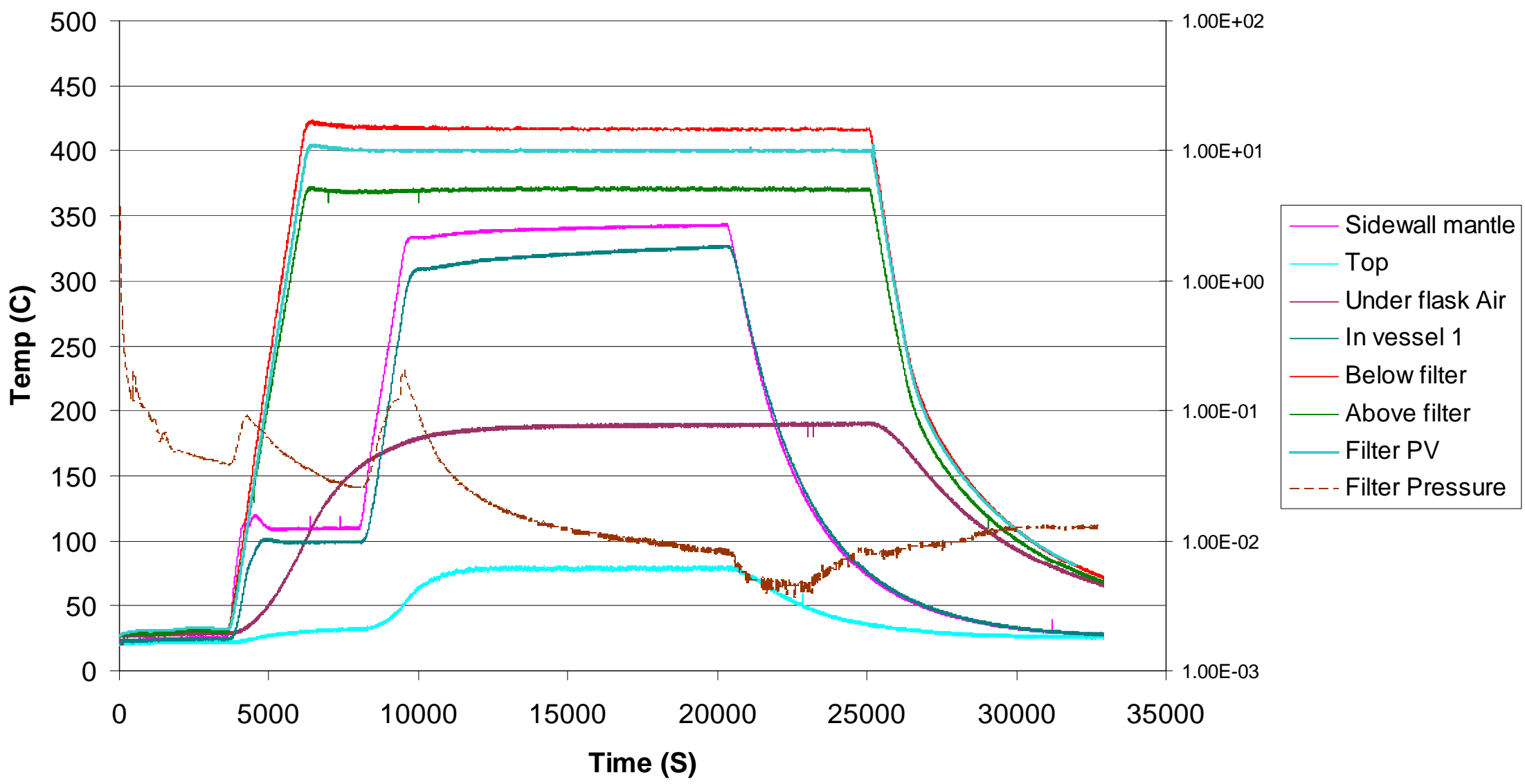

Figure 4. Typical data output from an experiment. Data from a $400^{\circ} \mathrm{C}$ cobalt and $410^{\circ} \mathrm{C}$ zinc run are shown. 


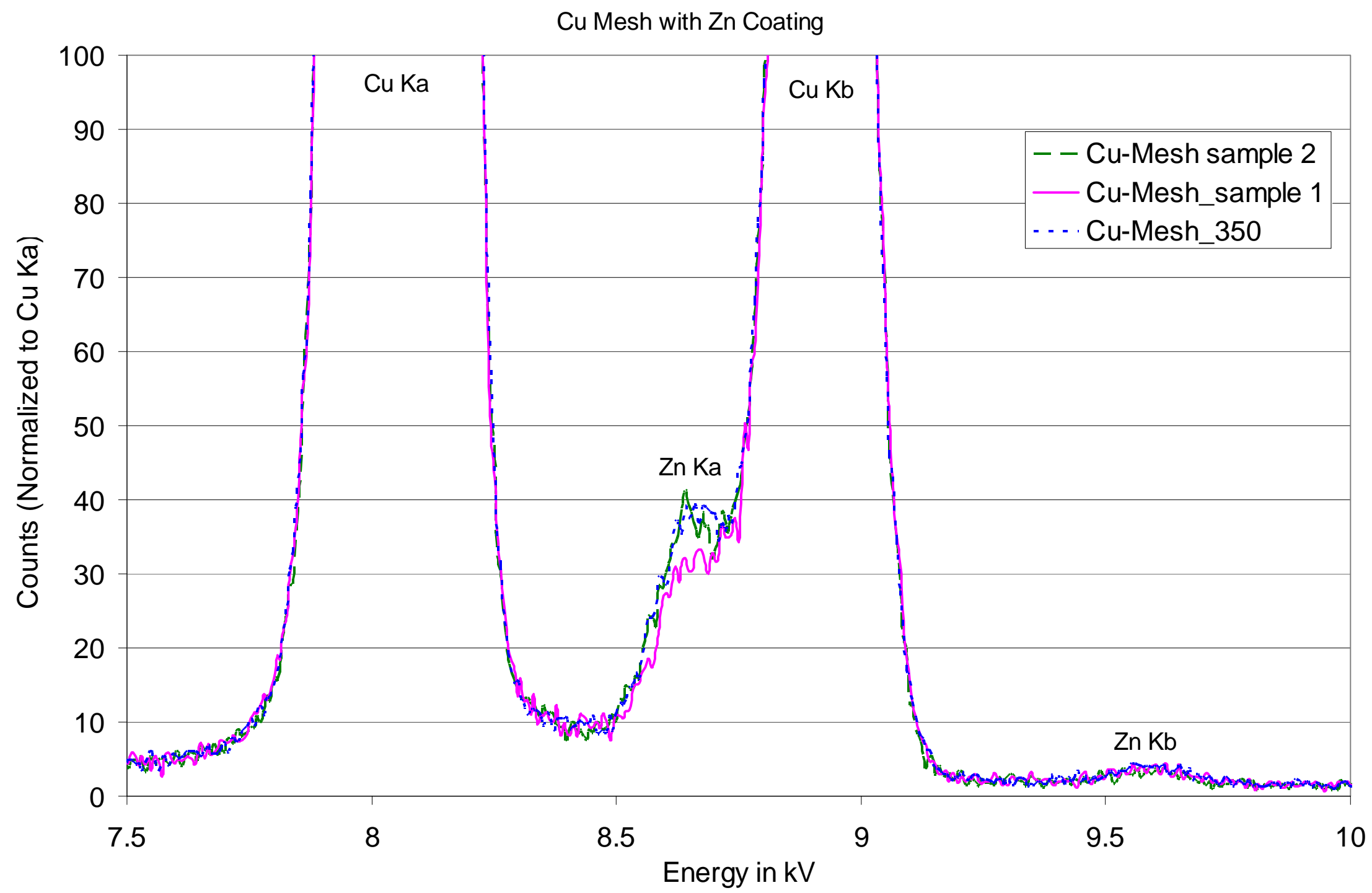

Figure 5. XPS results from the copper sample exposed at $400^{\circ} \mathrm{C}$. Note the presence of the $\mathrm{K} \alpha$ and $\mathrm{K} \beta$ peaks. 


\section{$3504 \mathrm{keV}$}
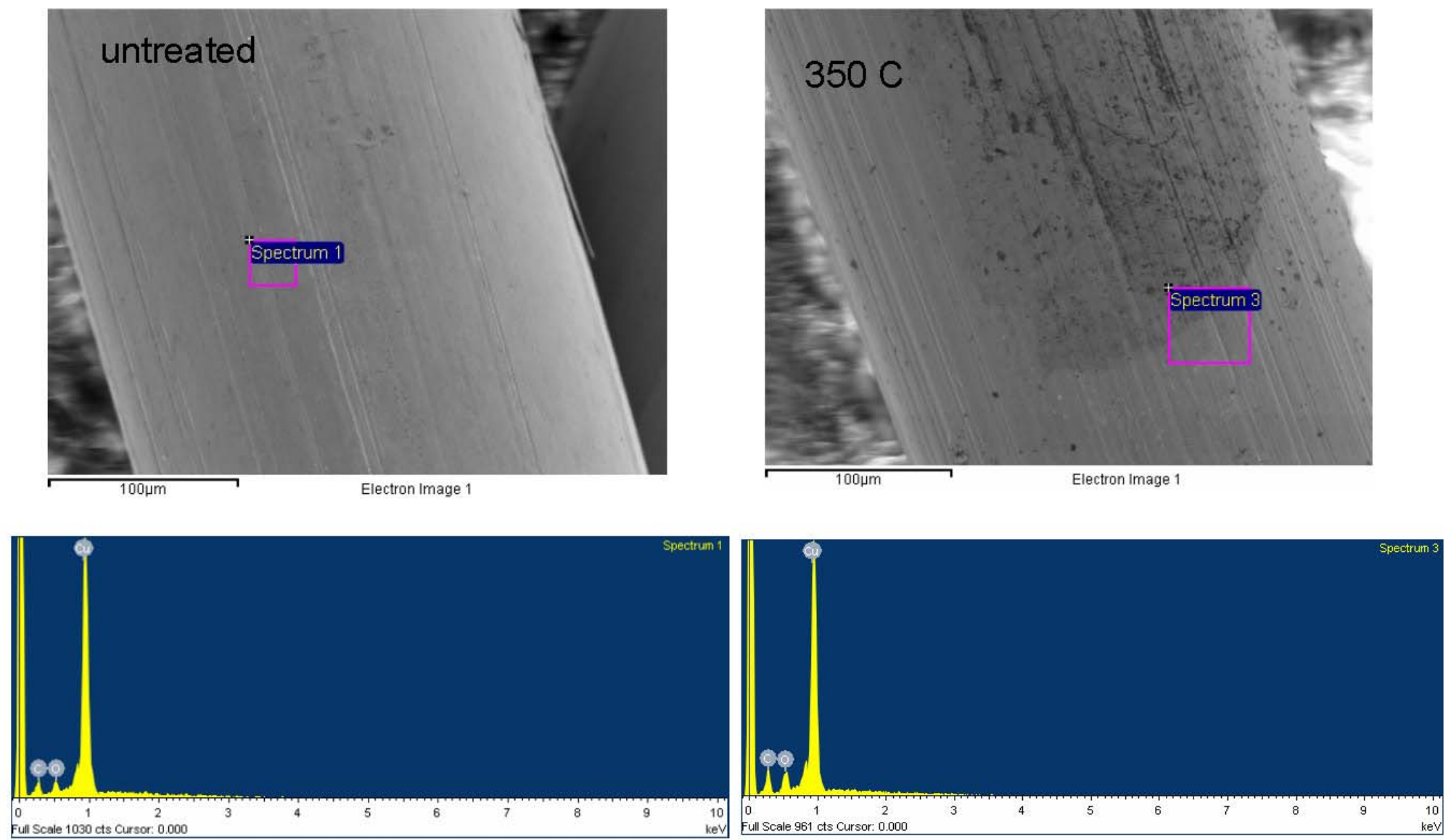

Figure 6. SEM and EDS results for areas of interest from the copper screen exposed at $350^{\circ} \mathrm{C}$. 


\section{C 4keV}
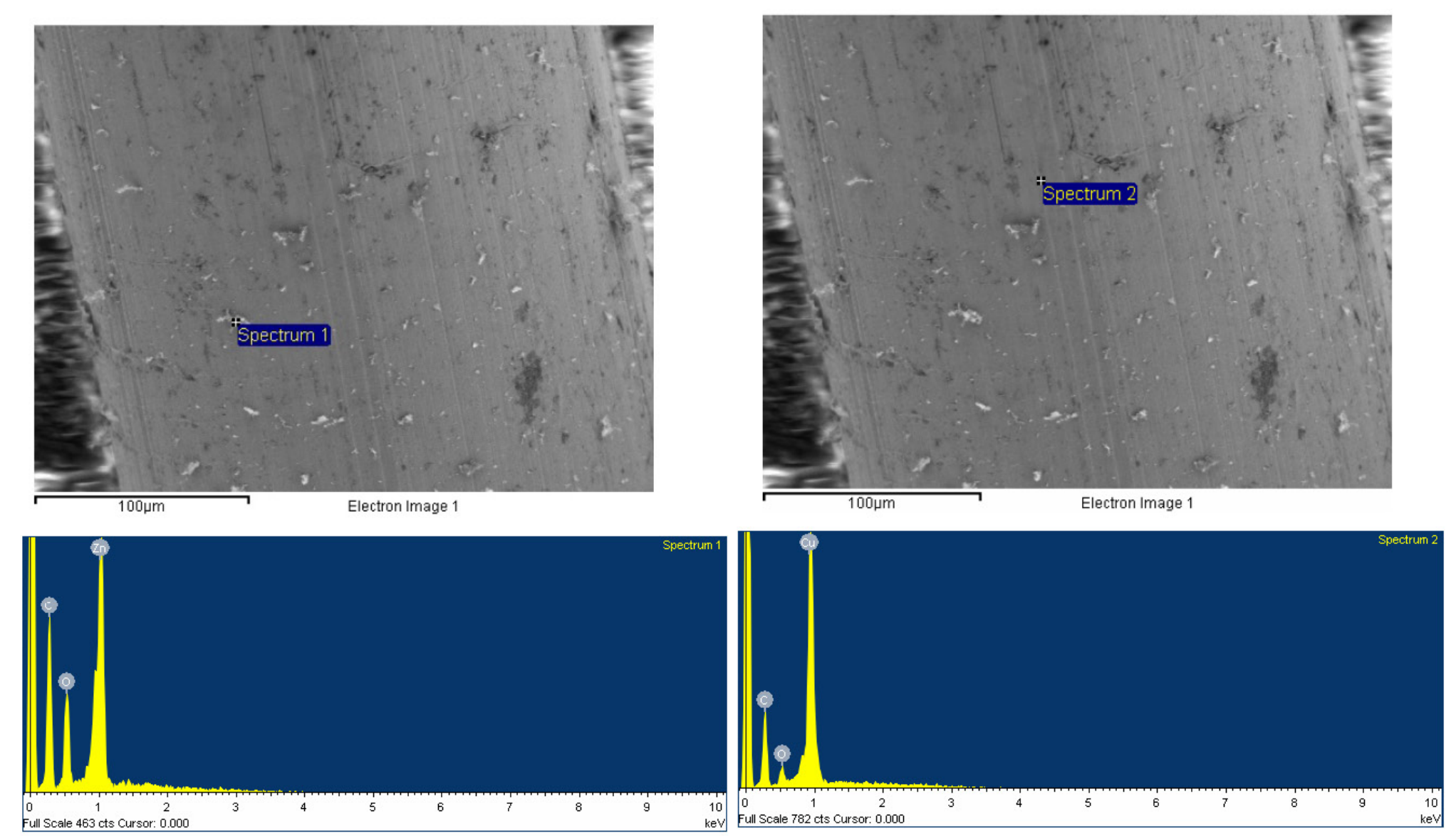

Figure 7. SEM and EDS results for areas of interest from the copper screen exposed at $400^{\circ} \mathrm{C}$. 


\section{$4504 \mathrm{KeV}$}
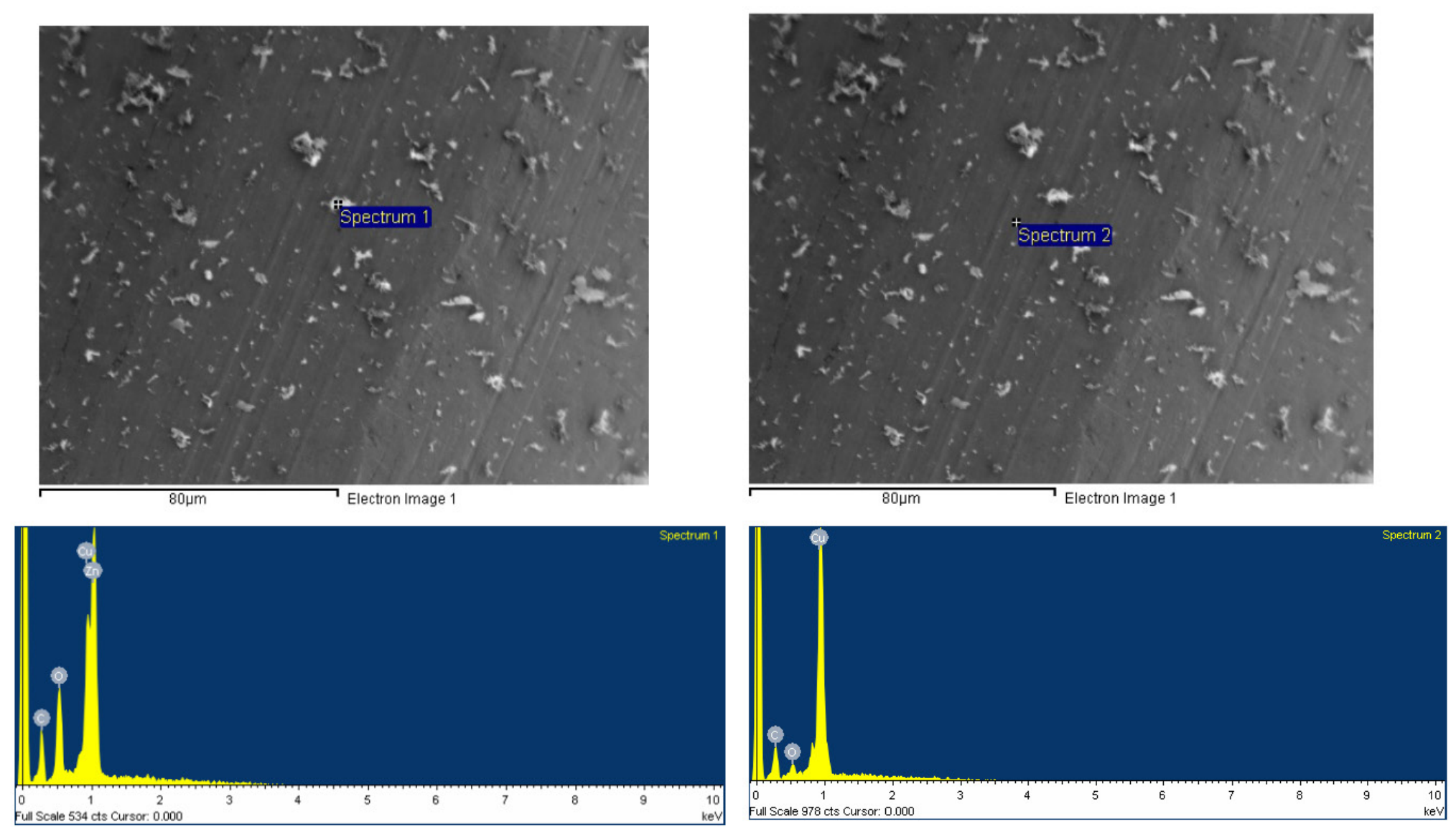

Figure 8. SEM and EDS results for areas of interest from the copper screen exposed at $450^{\circ} \mathrm{C}$. 


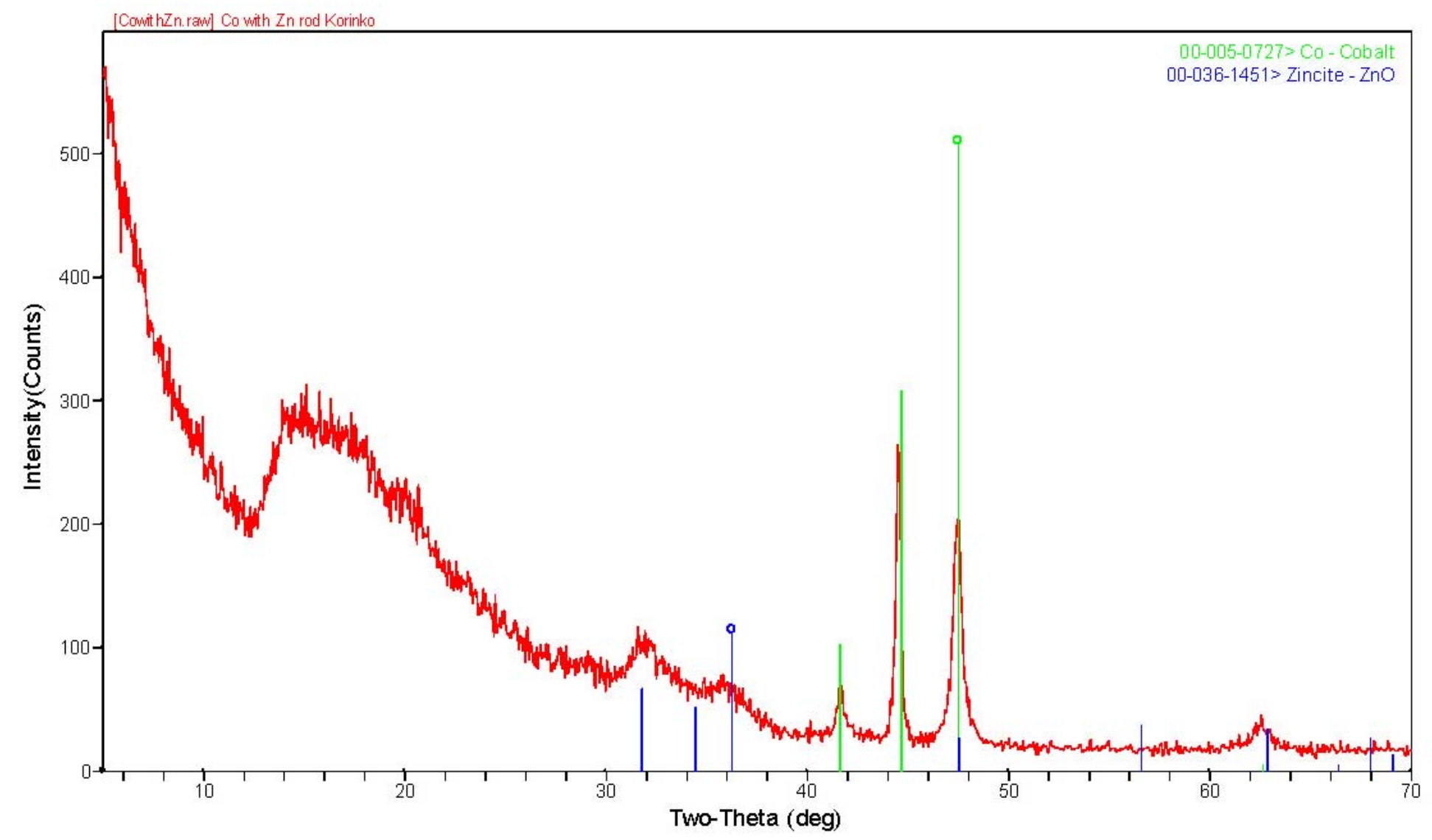

Figure 9. XRD results for the cobalt rod exposed at $400^{\circ} \mathrm{C}$. Note apparent absence of zinc and presence of only zinc oxide. 


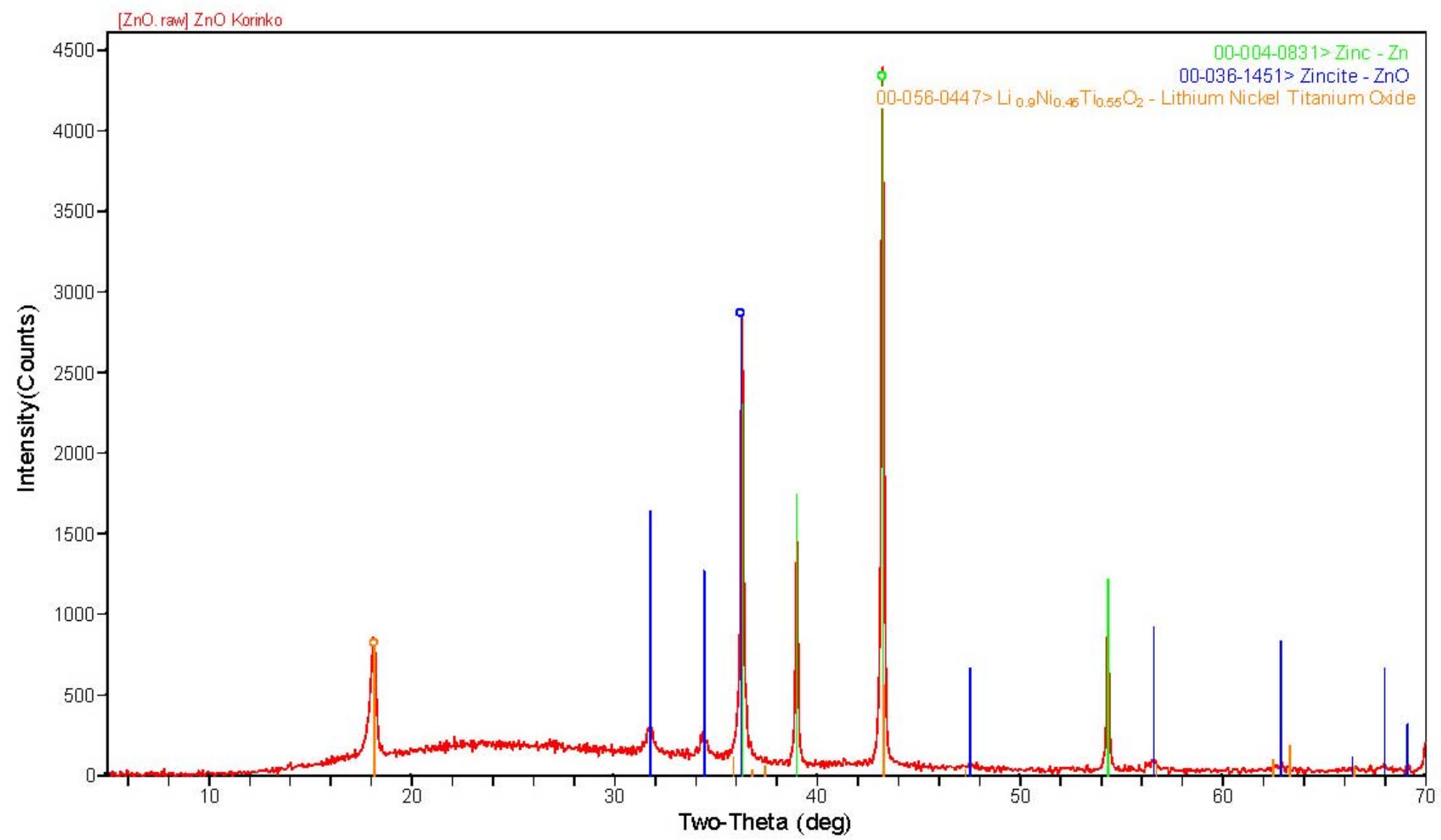

Figure 10. XRD results from zinc that was deposited in the vaporization chamber to confirm that zinc is primary species present. Note presence of zinc oxide as well. 